\title{
Surefire Antireflux Microcatheter
}

National Cancer Institute

\section{Source}

National Cancer Institute. Surefire Antireflux Microcatheter. NCI Thesaurus. Code

C154001.

A proprietary catheter with an expandable tip designed to increase infusion pressure while maintaining antegrade blood flow in order to deliver a higher concentration of agents to a target. 